\title{
LA FORMACIÓN DEL FILÓSOFO EN LAS ESCUELAS NEOPLATÓNICAS
}

\author{
LUIS GONZAGA ROGER CASTILLO \\ UNIVERSIDAD DE GRANADA. España
}

Resumen: El siguiente trabajo trata el plan de estudios empleado para la formación del filósofo en las escuelas neoplatónicas. Para ello se recurre a los textos originales, como el anónimo Prolegomena a la filosofía platónica, entre otros. Se reconstruyen los distintos ciclos que componían el plan de estudios y las obras filosóficas de Platón y Aristóteles que lo conforman. El plan de estudios buscaba el ascenso intelectual desde las realidades materiales hasta el plano de las ideas platónicas.

Palabras clave: Neoplatonismo, Antigüedad Tardía, Plan de estudios, Jámblico, Escuelas de filosofía.

\section{THE TRAINING OF A PHILOSOPHER IN THE NEOPLATONIC SCHOOLS}

Abstract: The following paper discusses the syllabus of the student of philosophy in the neoplatonic schools. Whenever possible, we will use original texts, as the anonymous Prolegomena to Platonic Philosophy, among others. We will reconstruct the parts of the syllabus, the use of the philosophical works of Plato and Aristotle. The entire syllabus aimed at the intellectual ascension from material realities to Plato's realm of forms.

Key Words: Neoplatonism, Late Antiquity, Syllabus, Iamblichus, Schools of Philosophy.

Recibido: 14.03.2016 - Aceptado: 25.05.2016

Correspondencia: Luis Gonzaga Roger Castillo

Email: luisrogercastillo@gmail.com

Licenciado en Derecho, Graduado en Filosofía y Teología.

Doctorando por la Universidad de Granada.

Centro de Estudios Bizantinos, Neogriegos y Chipriotas de Granada.

Dirección Institucional: Centro de Estudios Bizantinos, Neogriegos y Chipriotas de

Granada - Gran Vía de Colón 9, 2º 18001 Granada. 


\section{Introducción}

a filosofía de la Antigüedad Tardía, principalmente en la
vertiente neoplatónica, ha tenido una importancia capital en el
desarrollo del pensamiento y la sociedad. A lo largo de la Edad Media, los estudios tradicionales de trívium y quadrivium son una adaptación casi idéntica de su formulación neoplatónica. Aunque el pensamiento y los temas de esta filosofía han sido ampliamente estudiados, no se ha prestado la misma tención al proceso de formación de los filósofos en las escuelas y academias neoplatónicas. Sin embargo, el proceso formativo de las escuelas se consideraba de gran importancia. Ya Proclo, en su Comentario al Alcibiades I, se plantea diversas cuestiones acerca del orden de estudio de los diálogos de Platón que había establecido Jámblico ${ }^{1}$. Este orden jambliqueo será el principal estructurador del plan de estudios formativo en las escuelas del mediterráneo oriental de la Antigüedad Tardía. El presente estudio se centra principalmente en esta formación filosófica, intentando reconstruir, conforme a fuentes históricas, el orden del plan de estudios de los filósofos neoplatónicos, partiendo de su elaboración a partir de Jámblico y su desarrollo posterior.

\section{Curriculum y plan de estudios en las escuelas neoplatónicas}

El plan de estudios de mayor repercusión es el conocido como currículum de Jámblico. La noticia más detallada de este aparece en el tardío anónimo Prolegómenos a la filosofía de Platón ${ }^{2}$ del siglo VI, aunque a juzgar por las referencias anteriores, como las de Proclo, parece que trasmite con bastante fidelidad la atribución de su diseño a Jámblico. El plan de estudios se compone de dos partes, una de preparación ética y conceptual para la comprensión de la obra de Platón; la otra parte consiste en el estudio de los textos platónicos en un orden determinado. Paralelos o complementarios a este plan de estudios se encuentran los comentarios escritos por filósofos neoplatónicos a los diversos textos. Estos comentarios poseen amplio valor porque recogen buena parte de las explicaciones que sobre los textos se daban en las escuelas neoplatónicas y muestran la hermenéutica que se aplicaba a los mismos.

Desde una perspectiva general, el plan de estudios se divide en cuatro partes: Una parte introductoria de carácter ético-práctico; un primer ciclo que consiste en el estudio de obras de Aristóteles; un segundo ciclo consistente en

$1 \quad$ Proclo, Alcibiades I, p.8.

2 Seguimos la edición Anonymous Prolegomena to Platonic Philosophy (2011), detallada en la bibliografía. 
el estudio de obras de Platón y una parte posterior a los ciclos consistente en el aprendizaje de las materias teúrgicas ${ }^{3}$.

En rigor, el curriculum básico consistía en los dos ciclos mencionados ${ }^{4}$, de modo que la primera y la última parte podrían considerarse más bien como estudios opcionales.

\subsection{Estudios introductorios}

La primera parte del plan de estudios tiene carácter propedeútico y generalista. Se trata de una instrucción ética de carácter no sistemático. Consiste en el estudio del Enchiridion de Epicteto, los Versos aúreos, atribuidos a Pitágoras y algunos discursos de Isócrates, incluidos estos por los neoplatónicos alejandrinos. El inicio, por lo tanto, consiste en filosofía práctica, destinada a corregir el carácter y a fomentar el autoconocimiento del alumno para prepararlo en su conducta a la posterior contemplación intelectual de verdades más elevadas ${ }^{5}$

\subsection{Los Versos aúreos y los estudios pitagóricos}

Los Versos aúreos son un texto de 71 versos atribuido al propio Pitágoras. Atestiguan la gran influencia que ejerció el pitagorismo (o más exactamente, el neopitagorismo) sobre el neoplatonismo ya desde el tiempo de Porfirio, que escribe la Vida de Pitágoras. La existencia de otro posterior relato biográfico escrito por Jámblico, perteneciente a un grupo de escritos sobre las doctrinas del pitagorismo que ha llegado incompleto, permite suponer que junto con los Versos Aúreos se estudiaba la vida de Pitágoras como modelo de vida filosófica.

Los Versos áureos exponen un modelo ético de carácter espiritual y físico que conlleva elementos de carácter religioso que culminan en la purgación del alma, la liberación de la materia y la divinización. Los paralelismos con la doctrina plotiniana de retorno al Uno son bastante claros, lo que explica la inclusión del texto en la primera fase del plan de estudios. La existencia de varios comentarios neoplatónicos a los Versos Aúreos, permiten suponer la importancia que tenía en este periodo de aprendizaje. Hay constancia de cuatro comentarios, dos atribuidos a Proclo, uno a Jámblico y, el más relevante, otro atribuido a Hierocles, que ha llegado a nuestros días. El comentario de Hierocles

\footnotetext{
3 Marino de Neápolis, Proclo o de la felicidad, XXVI-XXVII.

4 Cf. Prolegomena, X; Marino de Neápolis, Proclo o de la Felicidad, XIIIXIV.

Cf. O’Meara (2003).
} 
incorpora gran cantidad de interpretaciones simbólicas. Probablemente, en las etapas posteriores del plan de estudios, estas interpretaciones se relacionasen con elementos de carácter teúrgico.

El simbolismo de la doctrina pitagórica aparece ya mencionado en las vidas de Pitágoras de Porfirio y Jámblico. En efecto, ambos mencionan la existencia de los símbolos pitagóricos, unas colecciones de frases enigmáticas cuyo sentido intentan desentrañar simbólicamente. Este estudio probablemente condujese al desarrollo del pensamiento analógico, de gran importancia en las interpretaciones de los diálogos de Platón en la fase posterior del currículum ${ }^{6}$.

\subsection{El Manual de Epicteto}

Otro de los textos, el Manual de Epicteto, es un texto perteneciente a la escuela estoica. La obra es una recopilación no sistemática de apuntes de las clases del filósofo estoico Epicteto (55-135). El propósito de formación moral de la obra resulta evidente desde su comienzo, cuando divide las cosas existentes entre aquellas que están bajo el propio control -la actitud y las virtudes- y aquellas que no -todas las demás-, de modo que aquel que pretenda ser feliz, únicamente ha de preocuparse por las primeras. Esto concuerda plenamente con el propósito neoplatónico de alejarse de las pasiones y purgar el espíritu para ascender en el retorno al Uno. Ha sobrevivido un comentario al Manual escrito por Simplicio. En el comentario, los términos estoicos son interpretados a la manera neoplatónica, relacionando la distinción del plano de lo inmutable y el plano de lo mutable con la distinción entre las cosas que dependen de uno mismo y las que no. El comentario de Simplicio arroja también alguna luz sobre el orden de estos estudios introductorios. Así, en el comentario a los capítulos VII y XXXVII del Manual, cita los Versos aúreos, empleándolos además para arrojar luz sobre el sentido del capítulo que comenta ${ }^{7}$. De aquí puede deducirse que los Versos aúreos precedían en el tiempo al estudio del Manual, puesto que los cita como algo ya conocido. En el comentario al capítulo LXXIV, Simplicio cita uno de los símbolos pitagóricos. Esto, sumado a los libros sobre doctrina pitagórica de Jámblico y Porfirio, permite suponer que paralelo al estudio de los Versos aúreos, se estudiaban otros aspectos de la doctrina pitagórica. Probablemente también se incluían diversos elementos de aritmética y geometría. Volviendo al Manual, es destacable además la interrelación entre las distintas obras de estos estudios introductorios, usando unas para explicar

\footnotetext{
$6 \quad$ Cf. Westerinck (2011),

7 Cf. Simplicio (1700).
} 
las otras, lo que dota de homogeneidad al estudio y permite ver la unidad del plan curricular.

\subsection{Los discursos de Isócrates}

O’Meara (2003) incluye en el curriculum el estudio de algunos discursos del orador Isócrates (s.IV a.C). Concretamente menciona los discursos $\mathrm{Ad}$ Demonicum, Ad Nicoclem, y Nicocles. No deja de ser peculiar la inclusión de la obra de Isócrates como preparación y exhortación práctica a la filosofía, dado que era contemporáneo de Platón y su modelo educativo, de corte retórico y no filosófico, se presentaba como contrapuesto con el modelo educativo de Platón. Se trata de una muestra más de la gran capacidad ecléctica y asimiladora del neoplatonismo. Como se verá, algo similar ocurre también con el primer ciclo, que asimila a Aristóteles. En cualquier caso, O’ Meara especifica que sólo se encuentran menciones a los discursos de Isócrates en los alejandrinos tardíos, porque lo que probablemente se tratase de una especialidad curricular exclusiva de esta escuela. O’Meara recoge así la opinión de Hadot (1984, p. 201), que es el primero en hacer notar este empleo de los textos isocráticos en la escuela alejandrina.

\section{Los misterios menores: El estudio de Aristóteles}

Tras el estudio introductorio de estas dos obras propedéuticas, se accedía al que podríamos denominar primer ciclo del plan de estudios, llamado introducción a los misterios menores, que consistía en el estudio de la obra de Aristóteles. Marino de Neápolis, en la Vida de Proclo, ofrece un testimonio de primera mano sobre la influencia de Aristóteles. Proclo tenía ya estudios previos de retórica y de filosofía aristotélica cuando comenzó a cursar el currículum neoplatónico junto con su maestro Siriano. Aristóteles, lejos de la contraposición contemporánea entre la doctrina de maestro y discípulo, continuaba siendo la preparación e introducción necesaria para la obra de Platón. Ya se ha apuntado antes en la relación de las distintas escuelas neoplatónicas. Las opiniones sobre Aristóteles en el neoplatonismo pueden condensarse en dos: una de carácter concordista, que sostiene que no hay oposición real entre Platón y Aristóteles. A esta vertiente pertenecerían, entre otros, Porfirio y Simplicio ${ }^{8}$. Siriano, por su parte, considera útil el estudio de Aristóteles, haciendo notar sin embargo las divergencias con el pensamiento de Platón y añadiendo el estudio de los contraargumentos neoplatónicos.

$8 \quad$ Cf. Remes (2008). 
En cualquier caso, el estudio de Aristóteles como parte fundamental del curriculum es innegable. La influencia aristotélica es ya patente desde Plotino, se acentúa en Porfirio y Jámblico y al menos desde la época de Proclo ya recibe la denominación de misterios menores. Se ha mencionado con anterioridad el interés de la escuela de Alejandría por la física aristotélica. Porfirio afirma que en Plotino se hallan latentes doctrinas peripatéticas, y que en su clase se leían los comentarios del peripatético Alejandro de Afrodisias?.

En la escuela de Atenas, como ya se ha dicho, Marino atestigua la presencia de Aristóteles en el curriculum neoplatónico: "En menos de dos años, Siriano leyó con él todos los tratados de Aristóteles, los de lógica, ética, política, física y el que está por encima de ésos, la ciencia teológica. Educado por ellos suficientemente, como por ciertos sacrificios preliminares y pequeños misterios, Siriano lo condujo a la iniciación mistérica de Platón de modo ordenado, y no, como dice el oráculo, transgrediendo las normas." ${ }^{10}$ Vemos que se expone aquí el primer ciclo del curriculum neoplatónico, denominándolo misterios menores, consistente en el estudio de Aristóteles. Este ciclo, además, es necesario para conducir a la iniciación mistérica de Platón de modo ordenado ${ }^{11}$.

El orden de mención de los tratados de Aristóteles indica un orden curricular. En primer lugar, encontramos en su disposición resonancias de los modelos tripartitos del estoicismo y el epicureísmo. Así, comienza por el estudio de la lógica. Esto hace referencia al conjunto de tratados recopilados bajo el nombre de Organon, como se conoció a este conjunto en la Edad Media. La mayor parte de los textos neoplatónicos que han llegado a nuestros días son comentarios a obras lógicas de Aristóteles, lo que manifiesta la importancia que se daba a esta materia.

\subsection{La lógica}

El estudio de la obra lógica se atestigua por la gran cantidad de comentarios de los diversos autores. Porfirio escribió dos comentarios a las Categorías de Aristóteles (uno de ellos, la Isagoge, de vital importancia). También comentaron esta obra, entre otros, Jámblico, Dexippo (h.350), Máximo de Éfeso, Simplicio, Ammonio (h.500), Olimpiodoro (s.VI), Elías, David el

9 Porfirio, Vida de Plotino, 14.

10 Marino de Neápolis, Proclo o de la felicidad, XIII, 315-320.

11 Lo que confirma la hermenéutica, radicalmente contrapuesta a la contemporánea, que aplicaban los filósofos neoplatónicos para entender la relación entre las filosofías platónica y aristotélica. 
armenio, Juan Filopón (490-530) y en occidente Mario Victorino y Boecio ${ }^{12}$. Dada la gran multitud de comentarios, parece ser el libro de texto básico para la introducción a la lógica aristotélica. Por número de comentarios, el siguiente parece ser los Primeros analíticos, que, entre otros, tienen comentarios de Jámblico, Marino de Neápolis, Juan Filopón y Boecio. También se conservan en menor número, comentarios a los Segundos analíticos, y al Sobre la interpretación. Así, las Categorías, los Primeros analíticos, los Segundos analíticos y Sobre la interpretación, debían ser los textos de estudio de la lógica en éste primer ciclo curricular, cosa que parece estar en concordancia con las alusiones que hace Ammonio en su Comentario a las Categorías ${ }^{13}$.

\subsection{La ética y política}

Según O’Meara (2003), para el estudio de la ética se empleaba como texto básico la Ética a Nicómaco, de Aristóteles. Han sobrevivido partes de un comentario de Porfirio sobre esta obra. Los neoplatónicos tardíos enmarcan en la denominada filosofía práctica tanto la Ética, como la Política, como los Económicos.

La ética actúa como base filosófica para la posterior contemplación. Si la primera etapa busca acostumbrar al estudiante de filosofía al modo de la vida filosófica, la ética consiste ya en un estudio racional y demostrativo, con carácter científico, del modo en que el hombre debe regirse a sí mismo. Dada la fuerte vinculación del plan de estudios con el concepto de virtud, como se verá, no es de extrañar que esta sea una materia básica del currículum filosófico.

Por otra parte, se otorgó en las escuelas neoplatónicas una gran importancia a la política como materia de aprendizaje, llegando incluso a la formación de un currículum específico. Las discusiones y variaciones sobre los diálogos platónicos que formaban parte de dicho estudio indican que no estaba definido con la misma nitidez que el plan general, como se verá posteriormente.

\subsection{La física}

Los textos aristotélicos que formaban parte del estudio de la física pueden también deducirse por los comentarios de los mismos. A tal efecto, recordemos que la escuela de Alejandría otorgó particular importancia al estudio de la obra física de Aristóteles. Así, en esta escuela, Olimpiodoro, y Filopón comentaron los Meteoros. Éste último también comentó Sobre la generación y

Cf. Fraile (1956).

13 Ammonio Hermias (1576), pp. 7-8. 
corrupción, Sobre la generación de los animales, Sobre el alma, y la Física. En la escuela de Atenas, se comentan también la Física, Sobre el cielo, Meteoros y el libro Sobre el alma, del que sabemos por Marino de Neápolis que se usaba como libro de texto en la escuela ${ }^{14}$. Jámblico también comentó el libro Sobre el alma, por lo que hace de éste el libro más común a las escuelas sobre tema físico, probablemente por su relación temática con el Fedón platónico, como se verá posteriormente, seguido por la Fisica y por los Meteoros ${ }^{15}$

\subsection{La metafísica}

El estudio de la ciencia teológica de Aristóteles, parece referirse principalmente al libro de la Metafísica. En efecto, el libro de la Metafísica se correspondía, para los neoplatónicos, con la mayor ciencia teorética, pero tenía un uso limitado debido a que contenía ataques a ciertas doctrinas platónicas. Siriano, ya se ha mencionado, introdujo la obra en el uso curricular, pero obligando a que el alumno estudiase las réplicas a los ataques aristotélicos. No obstante, conviene recordar que ya para Porfirio, en los escritos de Plotino estaban entreveradas las doctrinas peripatéticas "y también está condensada la Metafísica de Aristóteles"16. Probablemente de un intento de ajustar la Metafísica aristotélica a la doctrina neoplatónica proviene la posterior Teología de Aristóteles, en realidad un apócrifo construido sobre comentarios a partes de las Enéadas de Plotino, y de suma importancia por su influencia en la filosofía árabe del Medievo. Sobreviven comentarios de Siriano y Asclepio de Tralles.

El estudio de la Metafísica constituía el fin del primer ciclo curricular. Habiendo alcanzado el alumno la cúspide del estudio del ser -la teología, según lo entendían los neoplatónicos-, comienza el estudio de la obra de Platón, que consideraban referida a un plano ontológico superior.

Quizá se deba a esto que los tratados de Aristóteles, parecen tener un orden de correspondencia temática con los diálogos platónicos. Así, Marino de Neápolis parece indicar cierto aprendizaje por pares de obras cuando menciona que Proclo leyó con Siriano el Sobre el alma de Aristóteles y el Fedón de Platón, cuya temática, el alma, es común ${ }^{17}$. Las correspondencias se explicarían en el orden de los distintos planos del ser y de los conocimientos y virtudes aparejadas a cada uno de ellos. La correlación entre las obras aristotélicas y las platónicas,

$14 \quad$ Marino de Neápolis, Proclo o de la felicidad, XII, 295.

15 Cf. Jámblico (2002).

16 Porfirio, Vida de Plotino, 14.

17 Marino de Neápolis, Proclo o de la felicidad, XII, 295 
de efectuarse este estudio por pares, quizá tuviese la intención de acostumbrar al alumno a relacionar los distintos planos jerárquicos del ser, o bien se basase en la complementariedad de las enseñanzas platónicas y aristotélicas.

\section{Los misterios mayores: El estudio de Platón}

Una vez que el alumno alcanzaba el punto mayor de las ciencias teoréticas representado en la Metafísica de Aristóteles, el alumno pasaba al segundo ciclo, los misterios mayores. Consistía exclusivamente en el estudio de los diálogos de Platón, dispuestos en un orden determinado. Ese orden, al igual que hemos visto en los ciclos anteriores, tenía suma importancia porque suponía el orden adecuado de comprensión intelectiva del alumno.

Sobre este ciclo curricular encontramos noticias bastante concretas en la literatura clásica. Los Prolegomena a la filosofía de Platón, un manual anónimo de introducción didáctica a la filosofía de Platón datado en el siglo VI, es una de las principales fuentes de noticias sobre el orden, disposición, propósito y recursos pedagógicos del aprendizaje de los diálogos. Otra fuente de importancia, ya citada, es la Vida de Proclo de Marino de Neápolis, (también llamada Proclo o de la felicidad), particularmente al relatar las vicisitudes de Proclo al cursar el plan de estudios. Proclo ejerció una clara influencia, además, en la discusión sobre el adecuado orden e inclusión de los diálogos de Platón que forman parte del curriculum, si bien, la disposición primitiva se le atribuye ya a Jámblico.

\subsection{Orden de los diálogos}

El acceso a los misterios mayores consta a su vez de dos ciclos. Uno inicial que comprende el estudio de diez diálogos platónicos, y otro posterior de dos. El primer ciclo guía al alumno a través de un orden ascendente en la escala de las virtudes y el conocimiento. El segundo expone los niveles más elevados de la física y la teología como ciencias teoréticas. (O’Meara 2003). Así aparece en el siguiente pasaje de los Prolegomena:

"Podemos saltarnos la clasificación de todos estos, en primer lugar porque no es muy importante, Segundo, porque excedería el propósito del presente examen, y sólo mencionaremos el proceder del divino Jámblico. Los redujo todos a doce diálogos, de los cuales clasificó unos como físicos, otros como teológicos; estos doce los redujo a dos, el Timeo y el Parménides; el Timeo cubriendo todos los diálogos físicos y el Parménides todos los teológicos. El orden de estos es digno de ser discutido porque la práctica general es dar clase con estos diálogos. El primero en ser explicado es el Alcibíades, 
porque nos enseña a conocernos a nosotros mismos, y el orden adecuado es conocerse a sí mismo antes de conocer las cosas externas, porque difícilmente comprenderemos las demás cosas mientras seamos ignorantes de nosotros mismos. El último diálogo para ser expuesto es el Filebo, porque aquí Platón trata el Bien, que está más allá de todas las cosas; del mismo modo, también el diálogo debe venir después de todos los demás. Los que están en medio se disponen como sigue. Dado que las virtudes existen en cinco niveles distintos, - natural, ético, social, purificador y contemplativo-, debemos primero leer el Gorgias, porque trata un problema social; segundo, el Fedón, porque muestra el camino de la purificación, ya que la vida de purificación viene después de la vida social. Entonces llegamos al conocimiento de la realidad, que es adquirido por la virtud ética; esta realidad también se observa en los pensamientos o en las cosas. Después de los diálogos mencionados, deberíamos leer en cuatro lugar el Crátilo, que enseña acerca de las palabras; luego el Teéteto, que trata sobre cosas. Después de estos llegamos al... que trata la filosofía natural; el Fedro y el Banquete, que son contemplativos y tratan las cuestiones teológicas; y así llegamos a los diálogos perfectos, el Timeo y el Parménides"18.

El pasaje, como observa Westerink (2011) tiene una laguna en la que faltan dos diálogos. Coincide con O'Meara (2003) en la reconstrucción de la parte que falta: El Sofista y el Politico, insertados entre el Teeteto y el Fedro.

Proclo, por su parte, nos transmite una noticia sobre la división de los diálogos. Se trata del Comentario al Alcibíades I. Al igual que los Prolegomena, atribuye a Jámblico la susodicha división: "Y así me parece que por esta causa el divino Jámblico le atribuyó el primer lugar entre los diez diálogos en los que estima que se contiene toda la filosofía de Platón, y todo su desarrollo posterior se anticipa como si estuviera en forma seminal en este diálogo"19.

Es muy significativo que Proclo sitúe esta discusión tratando precisamente del Alcibíades I, que es el primero de los diálogos en orden de estudio. Además proporciona una importante herramienta filosófica para comprender la disposición de los mismos. En el primero, el Alcibiades I, se encuentra ya en potencia todo el desarrollo posterior, de modo que el estudio sucesivo de los demás diálogos implica un tránsito de la potencia al acto. El plan de estudios está estructurado a imagen de la emanación del Uno y del despliegue de la realidad. Es un tránsito de la potencia al acto, de lo ético a lo contemplativo, de lo múltiple a lo uno. Y bajo esta perspectiva resulta muy

\footnotetext{
18 Prolegomena, X, pp. 48-49.

19 Jámblico (1973), p.73 
clarificador el paralelismo con la disposición de las obras aristotélicas, que también siguen, como ya se ha apuntado, una escala ascendente hacia el mundo de las Ideas, que culmina con la Metafísica.

Los neoplatónicos de la Antigüedad Tardía, en las alusiones que han sobrevivido sobre los diálogos y a la obra de Jámblico, ilustran claramente este proceso ascendente cuando sintetizan la temática de cada diálogo temática en algunos casos, muy poco evidente para el lector contemporáneo. Lamentablemente, no se han transmitido fragmentos o noticias de Jámblico sobre todos los diálogos expuestos, pero las que se han conservado sirven para confirmar el ascenso intelectual paulatino en la temática. Así, además del ya mencionado Alcibiades I, se conservan:

- Fedón: Olimpiodoro (s.VI) transmite que "El objetivo de la presente discusión es demostrar, no que el alma es inmortal, sino simplemente que continúa existiendo tiempo después de su separación del cuerpo, y no como Jámblico piensa, que cada argumento demuestra la inmortalidad del alma"20. Aquí Olimpiodoro, crítico con Jámblico, no deja duda sobre la temática del diálogo; se trata del alma como subsistente fuera del cuerpo. Esta concepción temática probablemente explique su correlación complementaria con Sobre el alma de Aristóteles, a la que se aludió anteriormente.

-Sofista: Los Scholia Platonica reseñan que "El tema del presente diálogo, de acuerdo con el gran Jámblico, se refiere al demiurgo sublunar"21. A continuación se especifica que este demiurgo es "Hacedor de imágenes y purificador de las almas". Se observa cómo se produce un ascenso desde las almas hasta aquello que las purifica y que hace las imágenes o Ideas, es decir, la instancia inmediatamente superior. No supone el fin del ascenso porque además de este demiurgo que preside la generación, hay también un demiurgo celeste. Tratando esta cuestión, dicen: "El Arte de la División, de nuevo, imita la procesión de las entidades desde el Uno, como el demiurgo celeste y el demiurgo que preside sobre la generación; por esta razón, él también es un sofista"22. El Arte de la División es parte de la dialéctica, concretamente es la parte referente al estudio de las Categorías, sobre el que versa la Isagoge de Porfirio. Esta es una referencia muy importante sobre un empleo no evidente del aprendizaje

\begin{tabular}{ll}
\hline 20 & Ibid. p. 84. \\
21 & Ibid. p. 90. \\
22 & Ibid. .90.
\end{tabular}


lógico en las escuelas. El dialéctico o sofista, puede distinguir la procesión de los entes desde el uno, y por lo tanto está capacitado intelectualmente para ir ascendiendo por ella, remontándose hasta el origen. Los Scholia identifican al sofista del diálogo platónico con un demiurgo, aunque sea un hombre, capaz de ordenar y distribuir las cosas, debido a su conocimiento de la división. Debido a esta alusión, cabe apuntar la posibilidad de que el Fedón se estudiase en paralelo con las Categorías, por analogía con los referidos textos sobre el alma.

-Fedro: Hermias (s.V) recoge: "Todos estos han aclarado ciertas partes del diálogo, y han declarado el tema de todo el diálogo sobre esta base, pero de hecho debería haber un tema igualmente relevante a todas sus partes, igual que en el caso de un organismo vivo todas las partes están relacionadas con un principio. Por esta razón, Jámblico declaró que el tema es la belleza en cada nivel, como exponemos más abajo"23. Siguiendo la escala, aquí ya estamos en el plano de los trascendentales, la Idea de Belleza que lo permea todo.

-Filebo: Damascio (s.VI), hace referencia expresa a la línea de transmisión de la enseñanza. "El tema, de acuerdo con Jámblico y con la escuela de Siriano y Proclo, es la causa final de todas las cosas existentes, esto es, el Bien que penetra todas las cosas, (con esta restricción, no obstante, que no es el Bien trascendente, sino el Bien que se manifiesta en las cosas existentes mismas, hacia el que todas las cosas aspiran y que alcanzan, ya que el Bien trascendente es inalcanzable)"24. La línea sucesoria del plan de estudios queda clara. Desde Jámblico, diseñador del orden pedagógico, pasa a través de Siriano y Proclo hasta Damascio. En un nuevo ascenso, el tema que estudiaban aquí los alumnos era la idea de Bien, pero aquella manifestada, no la apofática e inefable.

-Timeo: Aquí comienzan los dos últimos libros, que son los más importantes. Ya hemos visto como se interpretaba el Alcibíades I, a modo de razón seminal dirigida hacia un fin más importante. Proclo, en el Comentario al Timeo, lo corrobora: "Porque el divino Jámblico está muy acertado al decir que toda la teoría de Platón se contiene en estos dos diálogos, el Timeo y el Parménides; ya que todo el tratamiento de los seres del cosmos y sobre el cosmos alcanza su culminación en ellos, y no hay orden de los entes que quede sin investigar" 25 .

\begin{tabular}{ll}
\hline 23 & Ibid. p. 92. \\
24 & Ibid. p. 100. \\
25 & Ibid. p. 106. \\
94 &
\end{tabular}


Más adelante se centra el tema: "El gran Jámblico considera más bien que debemos entender la diversidad en las expresiones de Platón como referida a la realidad objetiva, y ver como los opuestos de la naturaleza son vencidos por el Uno, y como el Uno se diversifica y cuanta variación presentan los mismos principios, existiendo de un modo en la Mente del Todo, haciéndose diferentes en el Alma, diferentes de nuevo en la Naturaleza, y por último en la Materia"26. Finalmente, el alumno neoplatónico está preparado para el estudio de lo referente al Uno. Ha ido elevándose paulatinamente por la escala antedicha y ahora, en estos dos diálogos, estudia la unidad inefable e inalcanzable y su relación con la multiplicidad.

-Parménides: Aquí culmina todo el sistema. Considerado como el diálogo más difícil, su temática también es difícil de precisar para los comentaristas. Para Damascio, el diálogo se refiere a lo inefable: “Que ni por opinión, ni por razonamiento discursivo, ni por el elemento intelectual del alma, ni por la intelección acompañada por la razón, se comprende el Inteligible; ni puede vislumbrarse por el ápice del intelecto, ni por la flor del intelecto, ni es cognoscible por esfuerzo mental alguno (...) es una proposición a la que, por insistencia del gran Jámblico, debemos acceder"27. El Uno, para Damascio y Jámblico, es completamente inalcanzable, como el Bien trascendente antedicho.

La alusión a la flor del intelecto en el fragmento de Damascio puede ser una referencia a las prácticas teúrgicas, concretamente las contenidas en los Oráculos Caldeos, hoy fragmentarios. Los alumnos neoplatónicos podían aprender la teúrgia de los Himnos Órficos o de los Oráculos, a modo de estudios superiores, una vez culminado el estudio de los diálogos platónicos con el Parménides. Marino de Neápolis refiere a este respecto como Siriano dio a escoger a Proclo y a su condiscípulo Domnino entre estudiar los Himnos o los Oráculos $^{28}$. El uno, no puede comprenderse ni vislumbrarse, pero la teúrgia quizá permitiera su experiencia. Recordemos en este sentido como la Teología Mística de Dionisio Areopagita, personaje desconocido pero tradicionalmente vinculado con la escuela de Proclo, propone el desconocimiento y la negación como un método de experiencia de esta unidad inefable. No obstante, el estudio del aprendizaje de la teúrgia excede el propósito del presente trabajo.

Ibid. p.112.

28 Marino de Neápolis. Proclo o de la felicidad. XXVI, 610, 615. 


\subsection{Cuestiones sobre la inclusión de los diálogos:}

Los Prolegomena comienzan con una discusión sobre la autenticidad de los diálogos: "Para establecer el verdadero orden, debemos primero mencionar los diálogos espurios, que no deben contarse. Los rechazados por consenso común son el Sísifo, el Demódoco, el Alcyon, el Erixias, y las Definiciones, que se atribuye a Espeusipo. Aparte de estos, quedan 36"29.

La discusión sobre los diálogos espurios ya data desde antiguo. Diógenes Laercio (s.III) ${ }^{30}$, cataloga como espurios por consenso, entre algunos otros, a los mismos que mencionan los Prolegomena. No menciona, sin embargo, el libro de las Definiciones 31 . "De estos, el divino Proclo rechaza el Epínomis por las razones dadas arriba; también descarta la República porque consta de muchos libros y no está escrita en forma dialógica, y las Leyes por la misma razón. También descarta las Cartas por la simplicidad del estilo, de modo que 32 diálogos es todo lo que queda. Si le añadimos los doce libros de las Leyes y los diez de la República, tenemos un total de 54 diálogos"32.

Entiéndase, claro está, que no se descartan aquí estos libros por dudar de su autenticidad. Según el anónimo, las razones que motivaron a Proclo a descartar la República y las Leyes fueron eminentemente curriculares. Son libros inapropiados para la enseñanza debido a su longitud y a que no estaban escritos en forma de diálogo. Aunque a juzgar por el comentario posterior del Anónimo, había ciertas discrepancias en las escuelas en cuanto a la utilización de estas obras en el plan curricular. De hecho, se conservan fragmentos de un Comentario a la República del mismo Proclo. La descripción de los tres tipos de estado, insertada por el anónimo al final de la exposición del curriculum, parece corresponder en la práctica de las virtudes políticas al proceso paulatino de purificación y unión. En este sentido cabe comprender la afirmación de Marino acerca de que Proclo empleaba la República y las Leyes, -junto con los tratados políticos de Aristóteles-, para la aprender y adquirir las virtudes políticas $^{33}$.

A continuación, prosigue el anónimo: "Suficiente sobre esto, pero como sin embargo algunas autoridades piensan que las Leyes y la República deberían también incluirse en el curriculum, debemos mencionar este tema. Hay tres

\footnotetext{
29 Prolegomena, X, p.47.

30 Diógenes Laercio, Vidas de los Filósofos Ilustres, III, 62.

31 Para la atribución a Espeusipo, Cf. Diógenes Laercio, V, 23.

32 Prolegomena, Ibid.

33 Marino de Neápolis, Proclo o de la felicidad, XIV, 335. 
tipos de constitución: el estado reformado, el estado adaptado y el estado ideal. El estado reformado se alcanza cuando corregimos nuestras malas acciones y retornamos a nuestra condición natural incorrupta; el estado adaptado, cuando ciertas leyes y costumbres del estado se dan por garantizadas; y el estado ideal cuando nada viene dado por la tradición, sino que todo es propiedad común, de modo que lo mío es tuyo y lo tuyo es mío, y las posesiones de los individuos son suyas propias y al mismo tiempo no lo son. El estado reformado se trata en las Cartas, el estado adaptado en las Leyes, y el estado ideal en la República"34.

Partiendo, por lo tanto, de un proceso purificatorio, se adquieren determinados elementos estables y fijos, culminando en la unión social a través de la unión en la propiedad. Esto reproduce los elementos neoplatónicos de ascenso mediante la purificación desde el plano de lo transitorio y corruptible, al plano de lo inmutable y fijo, concluyendo en el retorno a la unidad en el Uno. Hemos expresado las equivalencias en el Cuadro 1.

\section{Cuadro 1: Equivalencias entre los tipos políticos de estado y los rangos de ascenso ontológico}

\begin{tabular}{|c|c|c|c|c|}
\hline Libros & Clase de estado & $\begin{array}{c}\text { Fase de } \\
\text { ascenso }\end{array}$ & Características & Plano ontológico \\
\hline Cartas & $\begin{array}{c}\text { Estado } \\
\text { reformado }\end{array}$ & Purificación & $\begin{array}{c}\text { Retorno al } \\
\text { estado natural no } \\
\text { corrompido. }\end{array}$ & $\begin{array}{c}\text { Plano material } \\
\text { temporal y sujeto } \\
\text { al cambio }\end{array}$ \\
\hline Leyes & Estado adaptado & $\begin{array}{c}\text { Estabilidad } \\
\text { por las leyes }\end{array}$ & $\begin{array}{c}\text { Establecimiento de } \\
\text { leyes y costumbres } \\
\text { como garantía de } \\
\text { inmutabilidad. }\end{array}$ & $\begin{array}{c}\text { Plano espiritual } \\
\text { inmutable }\end{array}$ \\
\hline República & Estado ideal & Unión & $\begin{array}{c}\text { Todo en propiedad } \\
\text { común, las } \\
\text { posesiones de los } \\
\text { individuos son y } \\
\text { no son propias al } \\
\text { mismo tiempo. }\end{array}$ & Retorno al Uno \\
\hline
\end{tabular}

Sostiene O'Meara (2003) que a consecuencia de estas vacilaciones sobre la República y las Leyes, en algunas ocasiones se utilizarían como complemento del Gorgias, que a su vez serviría como libro de texto para las adquisición de las virtudes políticas en el primer ciclo. Por otra parte, ya en 
un momento curricular tan temprano como en los estudios introductorios a los ciclos, en el Comentario al Manual de Epicteto, atribuido a Simplicio, se cita el libro de las Leyes en el capítulo X. O’Meara añade al plan de estudio, en lo referido a las virtudes políticas, la Apología de Sócrates. De esta obra también aparece una cita en el capítulo LXXIX del comentario atribuido a Simplicio ${ }^{35}$.

\section{Conclusiones}

De lo antedicho se sigue que es posible una reconstrucción bastante precisa del curriculum de estudios neoplatónicos en sus distintos ciclos. En efecto, el orden de estudio era dispuesto con sumo cuidado y parece haber sido un tema recurrente entre los filósofos. De la importancia otorgada, se desprende que el orden de estudio de las materias era crucial en la formación del filósofo. Esto tiene sentido si se piensa que la adquisición de conocimiento tiene un carácter transformador para el estudiante, con repercusiones prácticas y no meramente erudito. Se pensaba que el orden adecuado de aprendizaje iba disponiendo la mente para su ascenso paulatino hasta las realidades superiores y el Mundo de las Ideas.

Además, la reconstrucción del curriculum proporciona herramientas valiosas para la hermenéutica de los textos neoplatónicos. Se ha aludido ya al respecto al tratar de la comprensión de la obra aristotélica. También destaca el profundo interés de los autores por precisar el tema exacto de cada uno de los diálogos platónicos, lo que proporcionaba una clave interpretativa. El eclecticismo filosófico que incluye elementos del estoicismo y el neopitagorismo, además del aristotelismo, nos transmite una imagen abierta de las escuelas. Además, los ya citados Prolegomena, son en su mayor parte un manual acerca de los métodos para interpretar los diálogos de Platón. El orden dispuesto en el plan de estudios inspira buena parte de tales métodos.

El propósito claramente ascensional de todo el plan, que alcanza el estudio del Uno y la experiencia divina en los posteriores estudios teúrgicos, revela una concepción soteriológica de la filosofía que continuará durante la Edad Media. La filosofía se vuelve previa a los estudios de teología, prolongando esta estructura de ascenso vertical. En Bizancio se preservarán las técnicas teúrgicas, transmitidas por Psellos y Miguel Itálico, en una tradición que probablemente llegue hasta Pletón. 


\section{BIBLIOGRAFÍA Y REFERENCIAS:}

\section{FUENTES PRIMARIAS:}

AMMONIO HERMIAS (1576) In praedicamenta Aristotelis comentarii, (B. Sylva, Trad. latina), Venecia.

DIÓGENES LAERCIO. (2007) Vidas de los filósofos ilustres. (C. García Gual, Trad. introducción y notas), Madrid: Alianza Editorial.

EPICTETO. (2004) Enquiridión. (J.M. García de la Mora, edición y traducción.) 2a Ed. Madrid: Anthropos.

JÁMBLICO. (1973) Iamblichi Chalcidensis in Platonis dialogos commentariorum fragmenta. (John M. Dillon, edición, texto bilingüe y traducción), Leiden: Brill.

(1997) Sobre los misterios egipcios. (E. A. Ramos Jurado, Introducción, traducción y notas), Madrid: Gredos.

(2002) De Anima. (Texto, traducción y comentario de John F. Finamore y John M. Dillon). Leiden: Brill.

(2008) Vida Pitagórica. Protréptico. (M. Periago Lorente, trad.), Madrid: Gredos.

MARINO DE NEÁPOLIS. (2004) Proclo o de la felicidad. (J.M. Garcia Ruiz; J. M. Álvarez Hoz, texto bilingüe, introducción y notas), Bilbao: Iralka.

PITÁGORAS (1995) Versos de Oro y Comentario de Hierokles a los Versos de oro de Pitágoras, en Pitágoras. (J.M. Bergua, Texto blingüe, traducción y notas.), Madrid: Clásicos Bergua.

PLOTINO. (1982) Enéadas I-II. (J. Igal, Trad.), Madrid: Gredos. (1985) Enéadas III-IV. (J. Igal, Trad.), Madrid: Gredos. (1998) Enéadas V-VI. (J. Igal, Trad.), Madrid: Gredos.

PORFIRIO. (1984) Sobre la abstinencia. (M. Periago Lorente, Trad.), Madrid: Gredos. (1987) Vida de Pitágoras. (M. Periago Lorente, Trad.), Madrid: Gredos. (2003) Isagoge. (J.J. García Norro; R. Rovira, Trads.), Madrid: Anthropos. (2008) Vida de Plotino. (J. Igal, Trad.), Madrid: Gredos.

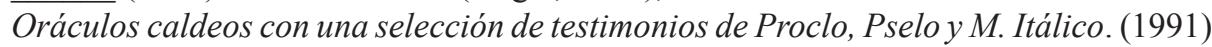
(F. García Bazán, Trad.), Madrid: Gredos.

PROCLO. (1971) Alcibiades I. A translation and commentary. (O’Neill, William. Trad. y Ed.) La Haya: Springer Science+Business Media Dordrecht.

Anonymous Prolegomena to Platonic Philosophy. (2011) (L.G.Westerink Ed. y Trad.), Wiltshire: Prometheus Trust.

SIMPLICIO. (1540) Summi peripatetici et platonici commentarium in decem Cathegorias Aristotelis, (G. Doroteo Veneto, Trad.), Venecia.

(1700) Epictetus, his morals: with Simplicius, his comment, (G. Stanhope, Trad.) London. 


\section{FUENTES SECUNDARIAS:}

CLARKE, E. C. \& DILlON, J. M. \& HERSHBELL, J. P. (2003) Introductio a Iamblichus, De Mysteriis. Atlanta: Society of Biblical Literature.

EDWARDS, M. (2000) Neoplatonic Saints. The lives of Plotinus and Proclus by their students. Liverpool: Liverpool University Press.

FRAILE, G. (1956) Historia de la filosofía Vol. I (9ª Ed.), Madrid: B.A.C.

HADOT, I. (2002) Simplicius or Priscianus? On the Author of the Commentary on Aristotle's "De Anima" (CAG XI): A Methodological Study. Fourth Series, 55, (2), 159-199.

LLOYD, A. C. (1998) The anatomy of neoplatonism. Oxford: Oxford University Press. O'MEARA, D. J. (1990) Pythagoras Revived. Mathematics and Philosophy in Late Antiquity. Oxford: Oxford University Press. (2003) Platonopolis. Platonic political philosophy in Late Antiquity. Oxford: Clarendon Press. (2006) Patterns of perfection in Damascius' Life of Isidore. Phronesis. 51, (1), 74-90.

REMES, P. (2008) Neoplatonism. Stocksfield: Acumen.

SHAW, G. (1995) Theurgy and the soul. The neoplatonism of Iamblichus. Pennsilvania: The Pennsilvania State University Press.

WESTERINK, L.G. (2011) Introduction, en Anonymous Prolegomena to Platonic Philosophy. Wiltshire: Prometheus Trust. 